\title{
Theoretical study of isomeric structures and low-lying electronic states of the vinyl radical $\mathrm{C}_{2} \mathrm{H}_{3}$
}

\author{
Jeng-Han Wang a , Hung-Chang Chang a , Yit-Tsong Chen ${ }^{\text {a,b,* }}$ \\ a Department of Chemistry, National Taiwan University, Taipei 106, Taiwan, ROC \\ 'Institute of Atomic and Molecular Sciences, Academia Sinica, P.O. Box 23-166, Taipei 106, Taiwan, ROC
}

Received 11 November 1995

\begin{abstract}
The molecular structure, intramolecular rearrangement and dissociation energy of $\mathrm{C}_{2} \mathrm{H}_{3}$ have been studied with high-level ab initio calculations using ACES II and MOLCAS-2 programs. In the structural calculations of $\mathrm{C}_{2} \mathrm{H}_{3}$, the optimized geometry and vibrational frequencies of $\tilde{\mathrm{X}}^{2} \mathrm{~A}^{\prime}$, the vertical electronic transition energies $\left(\tilde{\mathrm{A}}^{2} \mathrm{~A}^{\prime \prime} \leftarrow \tilde{\mathrm{X}}^{2} \mathrm{~A}^{\prime}\right.$ and $\tilde{B}^{2} A^{\prime} \leftarrow \tilde{X}^{2} A^{\prime}$ ), the vertical ionization potential and the permanent dipole moment of $\tilde{X}^{2} A^{\prime}$ have been computed. The harmonic vibrational frequencies and infrared intensities of $\mathrm{C}_{2} \mathrm{H}_{3} \tilde{\mathrm{X}}^{2} \mathrm{~A}^{\prime}$ obtained from this calculation will help the spectroscopic observation for the vibrational modes, most of which are unobserved. The calculated vertical transition energy, $25529 \mathrm{~cm}^{-1}$ for $\tilde{\mathrm{A}}^{2} \mathrm{~A}^{\prime \prime} \leftarrow \tilde{\mathrm{X}}^{2} \mathrm{~A}^{\prime}$, and the vertical ionization potential, $8.33 \mathrm{eV}$ from an MRCI method with atomic natural orbitals, are in excellent agreement with the experimental values of $24815 \mathrm{~cm}^{-1}$ and $8.25 \mathrm{eV}$, respectively. The vertical transition of $\widetilde{\mathrm{B}}^{2} \mathrm{~A}^{\prime} \leftarrow \tilde{\mathrm{X}}^{2} \mathrm{~A}^{\prime}$, predicted to be $43910 \mathrm{~cm}^{-1}$ from this work, will facilitate the experimental search for the undiscovered $\tilde{\mathrm{B}}$ state of $\mathrm{C}_{2} \mathrm{H}_{3}$ through spectroscopic observation. In calculating the intramolecular rearrangement in $\mathrm{C}_{2} \mathrm{H}_{3}$ $\tilde{\mathrm{X}}^{2} \mathrm{~A}^{\prime}$, using $\operatorname{CCSD}(\mathrm{T}) / \mathrm{Dunning}$ 's triple zeta polarizations, the non-classical structure with a hydrogen atom bridged between the $\mathrm{C}=\mathrm{C}$ bond has been found to lie at least $47 \mathrm{kcal} / \mathrm{mol}$ above the classical equilibrium structure. The calculation also indicates that the non-classical $\mathrm{C}_{2} \mathrm{H}_{3} \tilde{\mathrm{X}}^{2} \mathrm{~A}^{\prime}$ is an unstable isomer, corresponding to a transition state. The computed barrier for the tunnelling of $\alpha-\mathrm{H}$ in $\mathrm{C}_{2} \mathrm{H}_{3} \tilde{\mathrm{X}}^{2} \mathrm{~A}^{\prime}$ is also in excellent agreement with the upper bound limit of $<1500 \mathrm{~cm}^{-1}$ determined from high-resolution infrared spectroscopy. The dissociation energy of $\mathrm{C}_{2} \mathrm{H}_{3} \rightarrow \mathrm{C}_{2} \mathrm{H}_{2}+\mathrm{H}$ and the energy difference between the isomers of acetylene and vinylidene, calculated in the present study, are also consistent with experimental measurements.
\end{abstract}

\section{Introduction}

The vinyl radical, $\mathrm{C}_{2} \mathrm{H}_{3}$, is one of the most important transient hydrocarbons in flame chemistry [1-3]. The mechanisms for the decomposition of $\mathrm{C}_{2} \mathrm{H}_{3}$, such as thermal decomposition, reactions with

\footnotetext{
* Corresponding author. Fax: +88623620200 ;

E-mail; ytchen@po.iams.sinica.edu.tw.
}

hydrogen [4] and oxygen [5] etc., have demonstrated to be of fundamental importance in comirustion processes. It is also a significant chemical intermediate in various chemical reactions, e.g. the addition to and the polymerization of an acetylenic bond, and the decomposition of ethenoid compounds. Moreover, owing to its important role in stereochemistry, vinyl radicals have attracted the interest of organic chemists for a long time [6]. 


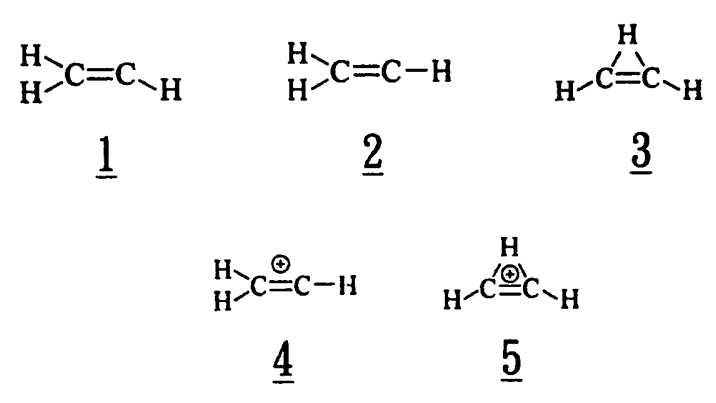

Fig. 1. The isomeric structures of vinyl radical and vinyl cation.

Geometry calculations for $\mathrm{C}_{2} \mathrm{H}_{3}$ in the ground $\left(\tilde{\mathrm{X}}^{2} \mathrm{~A}^{\prime}\right)$ and the first excited $\left(\tilde{\mathrm{A}}^{2} \mathrm{~A}^{\prime \prime}\right)$ electronic states have also been the subject of many theoretical studies [7-9]. The calculated planar structures with $C_{S}$ symmetry ( 1 in Fig. 1) in the $\tilde{\mathrm{X}}^{2} \mathrm{~A}^{\prime}$ and the $\tilde{\mathrm{A}}^{2} \mathrm{~A}^{\prime \prime}$ states of $\mathrm{C}_{2} \mathrm{H}_{3}$, and their associated electronic energies were used in the analysis of the low-resolution $\left(\Delta \nu \approx 45 \mathrm{~cm}^{-1}\right)$ electronic $\tilde{\mathrm{A}}^{2} \mathrm{~A}^{\prime \prime} \leftarrow \tilde{\mathrm{X}}^{2} \mathrm{~A}^{\prime}$ absorption spectrum observed by Hunziker et al. [7]. In the observed vibrationally resolved electronic absorption spectrum of $\mathrm{C}_{2} \mathrm{H}_{3}$, the attribution for the lack of rotational features as due to the low instrumental resolution or the nature of molecular predissociation remains uncertain [7]. The ionization potential of $\mathrm{C}_{2} \mathrm{H}_{3}$ reported from several experiments [10-12], ranging from 8.95 to $8.25 \mathrm{eV}$, has also been the subject of some controversy.

Although the vibrational frequencies and dipolemoment derivatives of $\mathrm{C}_{2} \mathrm{H}_{3} \quad \tilde{\mathrm{X}}^{2} \mathrm{~A}^{\prime}$ were calculated from generalized valence bond wavefunctions many years ago [13], the $\nu_{7}$ vibrational band at $895 \mathrm{~cm}^{-1}$ reported by Kanamori et al. [14] in gas-phase spectroscopy $\left(\sim 900 \mathrm{~cm}^{-1}\right.$ in matrix isolation by Shepherd et al. [15]) has so far been the only vibrational observation. In the high-resolution infrared spectroscopy of $\mathrm{C}_{2} \mathrm{H}_{3}$, Kanamori et al. have reported the radical to be of $\mathrm{C}_{2 \mathrm{v}}$ effective symmetry ( 2 in Fig. 1), referring to a tunnelling motion in the double-minimum potential due to the rocking $\alpha-\mathrm{H}$ in $\mathrm{C}_{2} \mathrm{H}_{3}$ (as shown in Fig. 2a). The tunnelling was evidenced by (i) the spectroscopic splitting of the vibrational components in the excited $v_{7}=1$ and in the ground vibrational states, and (ii) the spectral intensity ratio of $3: 1$ for the ortho- and para-nuclear-spin statistical weights, which can only be rationalized by a $C_{2 v}$ molecular symmetry in $\mathrm{C}_{2} \mathrm{H}_{3} \quad \tilde{\mathrm{X}}^{2} \mathrm{~A}^{\prime}$. The energy barrier for the rocking motion was estimated to be $<1500 \mathrm{~cm}^{-1}$ from the observed spectrum [14], which is lower than the previous predictions from some relatively low-level calculations $[8,13]$. In this study, we have calculated the nine vibrational normal modes and infrared intensities of $\mathrm{C}_{2} \mathrm{H}_{3} \tilde{\mathrm{X}}^{2} \mathrm{~A}^{\prime}$, and have tried to accurately determine the barrier of the $\alpha-\mathrm{H}$ rockin $\mathrm{E}$ motion in $\mathrm{C}_{2} \mathrm{H}_{3}$.

In contrast to the remarkable isomerization process in $\mathrm{C}_{2} \mathrm{H}_{3}^{+}$(as shown in Fig. 2b) extensively investigated both experimentally [16] and theoretically [17], the study about the isomerization of $\mathrm{C}_{2} \mathrm{H}_{3}$ (Fig. 2c) has been relatively little reported. While the energy difference between classical (4 in Fig. 1) and non-classical (5 in Fig. 1) structures of $\mathrm{C}_{2} \mathrm{H}_{3}^{+}$is only $\sim 4 \mathrm{kcal} / \mathrm{mol}$, Harding predicted the barrier for the $\mathrm{H}$-migration in $\mathrm{C}_{2} \mathrm{H}_{3}$ as high as $57 \mathrm{kcal} / \mathrm{mol}$ in an earlier study [18]. In this paper, we shall report our re-examination of the energy difference between the classical (1 in Fig. 1) and non-classical (3 in Fig. 1) structures of $\mathrm{C}_{2} \mathrm{H}_{3}$ with high-level ab initio calculations. The very recent calculation of the methylcarbyne-vinyl isomerization conducted by Nielsen et al. is worth noticing [19]. The calculated isomerization barrier and energy difference from methylcarbyne to vinyl radical are 9 and $-49 \mathrm{kcal} / \mathrm{mol}$, respectively, in the doublet potential, and 57 and -3 $\mathrm{kcal} / \mathrm{mol}$ in the quartet. The calculations have signified that the spectroscopic observation from vinyl to methylcarbyne is much more difficult than the reversed isomerization process.

Of particular interest to us with the vinyl radical

a.

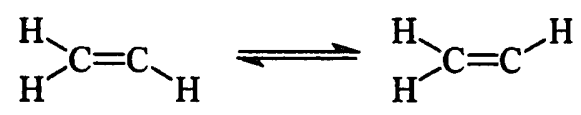

b. $\quad \mathrm{H}^{-} \mathrm{C} \stackrel{\oplus}{=} \mathrm{C}-\mathrm{H}$<smiles>C=C</smiles><smiles>C=CC=C</smiles>

Fig. 2. The intramolecular rearrangements in vinyl radical and vinyl cation. 
is to experimentally investigate the isomerization and the dissociation processes of $\mathrm{C}_{2} \mathrm{H}_{3} \tilde{\mathrm{X}}^{2} \mathrm{~A}^{\prime}$ in our laboratory by vibration-rotationally state-selective laser spectroscopy, such as stimulated emission pumping (SEP) [20] or two-color (IR-UV) laser-induced grating (LIG) [21]. To facilitate the experimental performance in the SEP and LIG spectroscopies, we have calculated the vertical electronic transition frequencies. Owing to the likely predissociation in the first excited electronic state $\left(\tilde{\mathrm{A}}^{2} \mathrm{~A}^{\prime \prime}\right)$ of $\mathrm{C}_{2} \mathrm{H}_{3}$ as discussed by Hunziker et al. [7], we have sought an alternative and calculated the second excited electronic state of the radical. We have also calculated the vertical ionization potential of $\mathrm{C}_{2} \mathrm{H}_{3}$ to compare with the experimental result [12] to test the accuracy of the computational process. In this paper, we shall also report the calculations of the energy required for the $\mathrm{C}-\mathrm{H}$ bond cleavage in the dissociation of $\mathrm{C}_{2} \mathrm{H}_{3} \rightarrow \mathrm{H}+\mathrm{HCCH}$ (acetylene) or $\mathrm{C}_{2} \mathrm{H}_{3} \rightarrow \mathrm{H}+\mathrm{H}_{2} \mathrm{CC}$ (vinylidene). The calculated results will show that the isomerizations are energetically above the dissociation threshold of $\mathrm{C}_{2} \mathrm{H}_{3} \rightarrow \mathrm{H}$ $+\mathrm{HCCH}$.

This paper is organized as follows. In Section 2, we will describe the computational details for the calculations of the molecular structure, intramolecular rearrangement and dissociation of $\mathrm{C}_{2} \mathrm{H}_{3}$ using ACES II [22] and MOLCAS-2 [23] programs. For the molecular structure of $\mathrm{C}_{2} \mathrm{H}_{3}$, we have calculated (i) the equilibrium geometry and vibrations of the ground electronic state $\left(\overline{\mathrm{X}}^{2} \mathrm{~A}^{\prime}\right)$, (ii) the isomeric structures on the ground electronic potential, (iii) the vertical transitions from the ground $\left(\tilde{X}^{2} A^{\prime}\right)$ to the first $\left(\tilde{\mathrm{A}}^{2} \mathrm{~A}^{\prime \prime}\right)$, and to the second $\left(\tilde{\mathrm{B}}^{2} \mathrm{~A}^{\prime}\right)$ excited electronic states, respectively, (iv) the vertical ionization potential, and $(v)$ the permanent dipole moment of $\tilde{\mathrm{X}}^{2} \mathrm{~A}^{\prime}$. Calculations of the intramolecular rearrangement in $\mathrm{C}_{2} \mathrm{H}_{3}$ include isomerization and $\alpha$ - $\mathrm{H}$ rocking motion as shown in Fig. 2. In the study of the dissociation in $\mathrm{C}_{2} \mathrm{H}_{3} \tilde{\mathrm{X}}^{2} \mathrm{~A}^{\prime}$, we have calculated the dissociation energies of $\mathrm{C}_{2} \mathrm{H}_{3} \rightarrow \mathrm{H}+\mathrm{HCCH}$, and of $\mathrm{C}_{2} \mathrm{H}_{3} \rightarrow \mathrm{H}+\mathrm{H}_{2} \mathrm{CC}$. The energy difference between the isomers of acetylene and vinylidene has also been computed. In Section 3, we will discuss the calculated results obtained in the present study using high-level ab initio methods with various efficient basis sets. Concluding remarks will be addressed in Section 4.

\section{Computational details}

All of the calculations carried out in this study were executed on an IBM RISC $6000 / 590$ computer. The computational schemes for molecular structure, intramolecular rearrangement and dissociation of $\mathrm{C}_{2} \mathrm{H}_{3}$ using the programs of ACES II and MOLCAS-2 will be described in the following.

\subsection{Molecular structure}

\subsubsection{Equilibrium geometry and vibrations of $\mathrm{C}_{2} \mathrm{H}_{3}$ $\tilde{X}^{2} A^{\prime}$}

Using the ACES II program, we have optimized the ground electronic structure of $\mathrm{C}_{2} \mathrm{H}_{3}$. The $\mathrm{ab}$ initio methods, including many body perturbation theory (MBPT) and coupled cluster (CC), have been employed in the full optimization for the nine internal co-ordinates in $\mathrm{C}_{2} \mathrm{H}_{3}$. The basis sets for the carbon and hydrogen atoms of $\mathrm{C}_{2} \mathrm{H}_{3}$ were $6-31 \mathrm{G}^{*}$ * and Dunning's DZP, TZP, TZ2P and PVTZ. In the optimization, UHF MOs were used as approximate starting wavefunctions, and the vinyl radical was set to be of $\mathrm{C}_{1}$ symmetry. The labelling for each atom in the equilibrium structure of $\mathrm{C}_{2} \mathrm{H}_{3}$ is shown in Fig. 3 . The completion of the optimization was reached at an energy gradient of $\leqslant 1 \times 10^{-4}$ hartree/bohr. The optimized geometry of the ground electronic state of $\mathrm{C}_{2} \mathrm{H}_{3}$, using various methods and basis sets, together with the calculated rotational constants are listed in Table 1. Since the dihedral angles in the optimized geometry of the ground electronic state of $\mathrm{C}_{2} \mathrm{H}_{3}$ are very small $\left(\leqslant 0.02^{\circ}\right.$ in all of the calculations) and are not shown in Table 1 , the structure is essentiaily planar. The symmetry of the ground electronic state of $\mathrm{C}_{2} \mathrm{H}_{3}$ is therefore an $\mathrm{A}^{\prime}$ representation belonging to the $\mathrm{C}_{\mathrm{S}}$ molecular symmetry group, i.e. $\tilde{\mathrm{X}}^{2} \mathrm{~A}^{\prime}$.

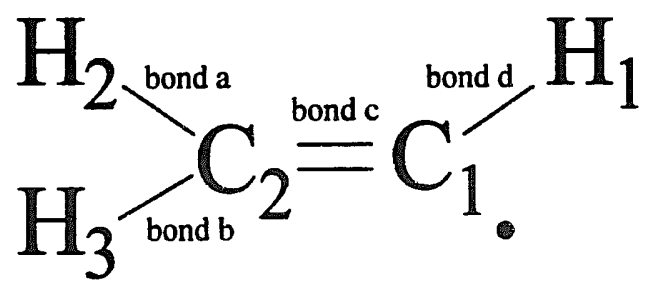

Fig. 3. The labelling for each atom in classical $\mathrm{C}_{2} \mathrm{H}_{3}$. The core electrons $\left(1 \mathrm{~s}^{2}\right)$ of the carbon are not shown. 


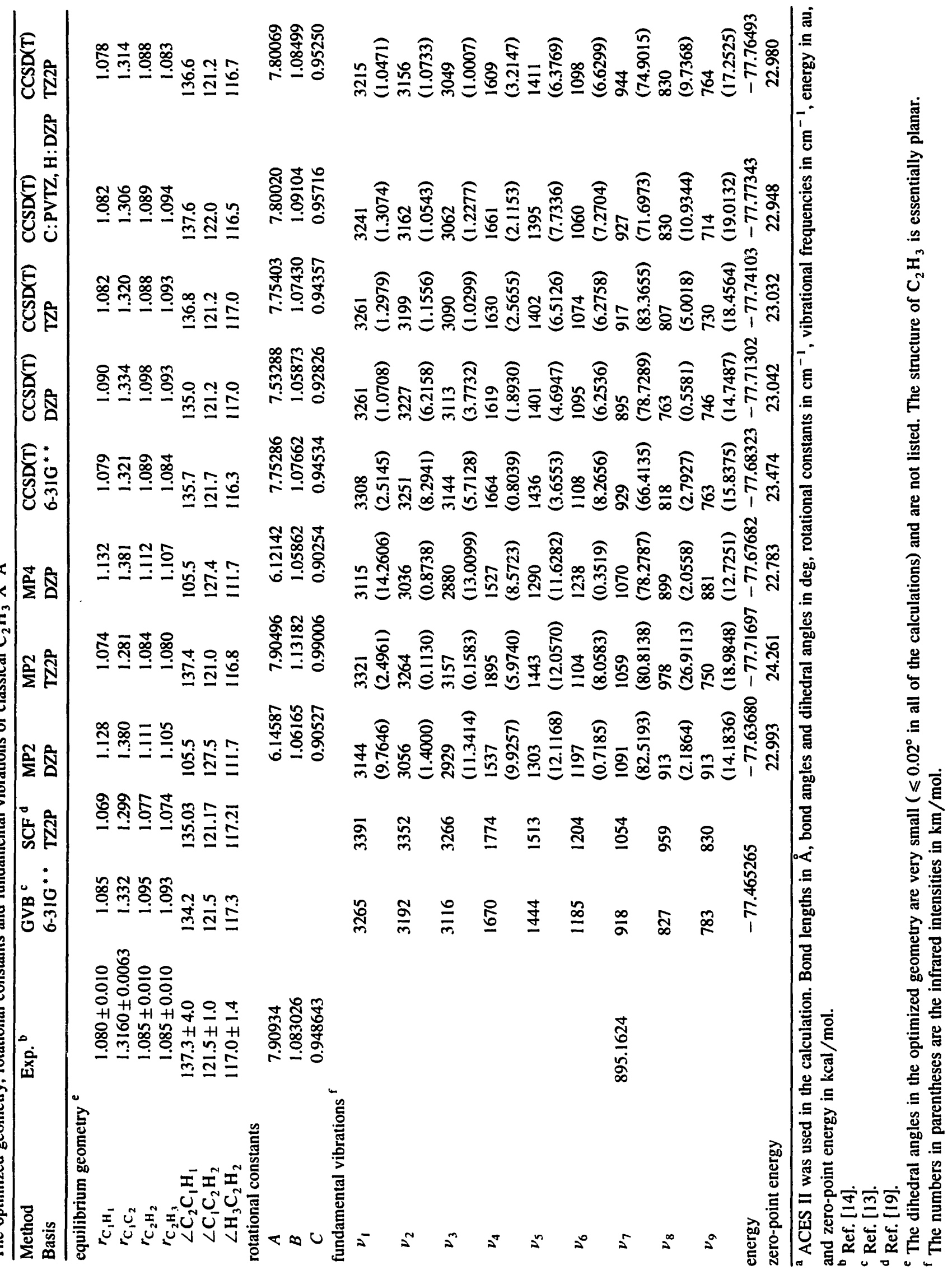



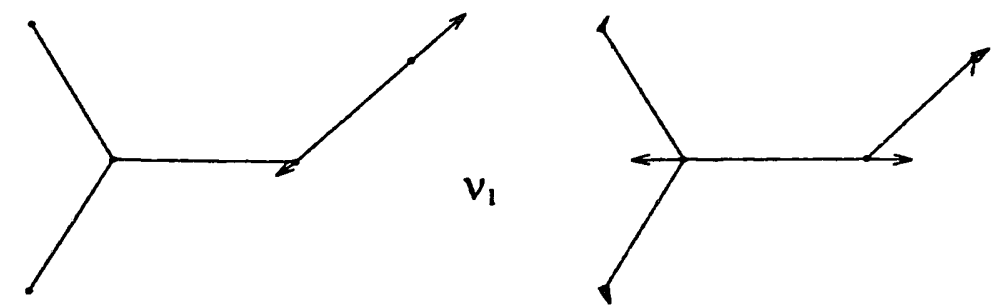

$\mathbf{V}_{4}$
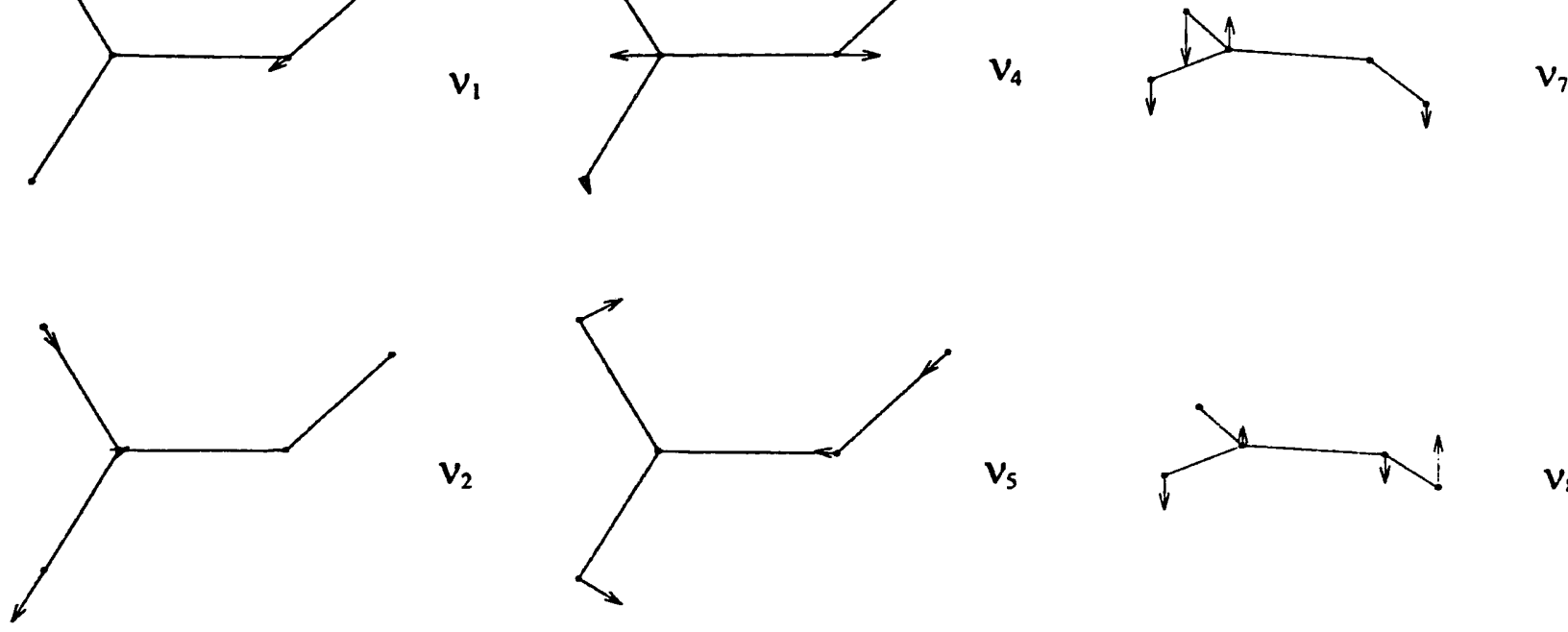

$\mathbf{V}_{2}$

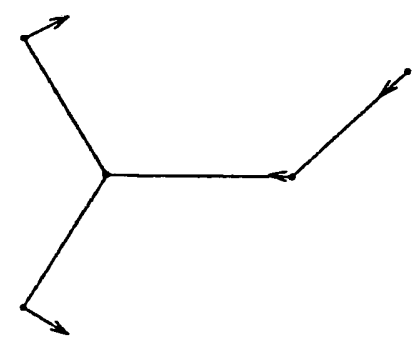

$\mathbf{V}_{\mathbf{S}}$
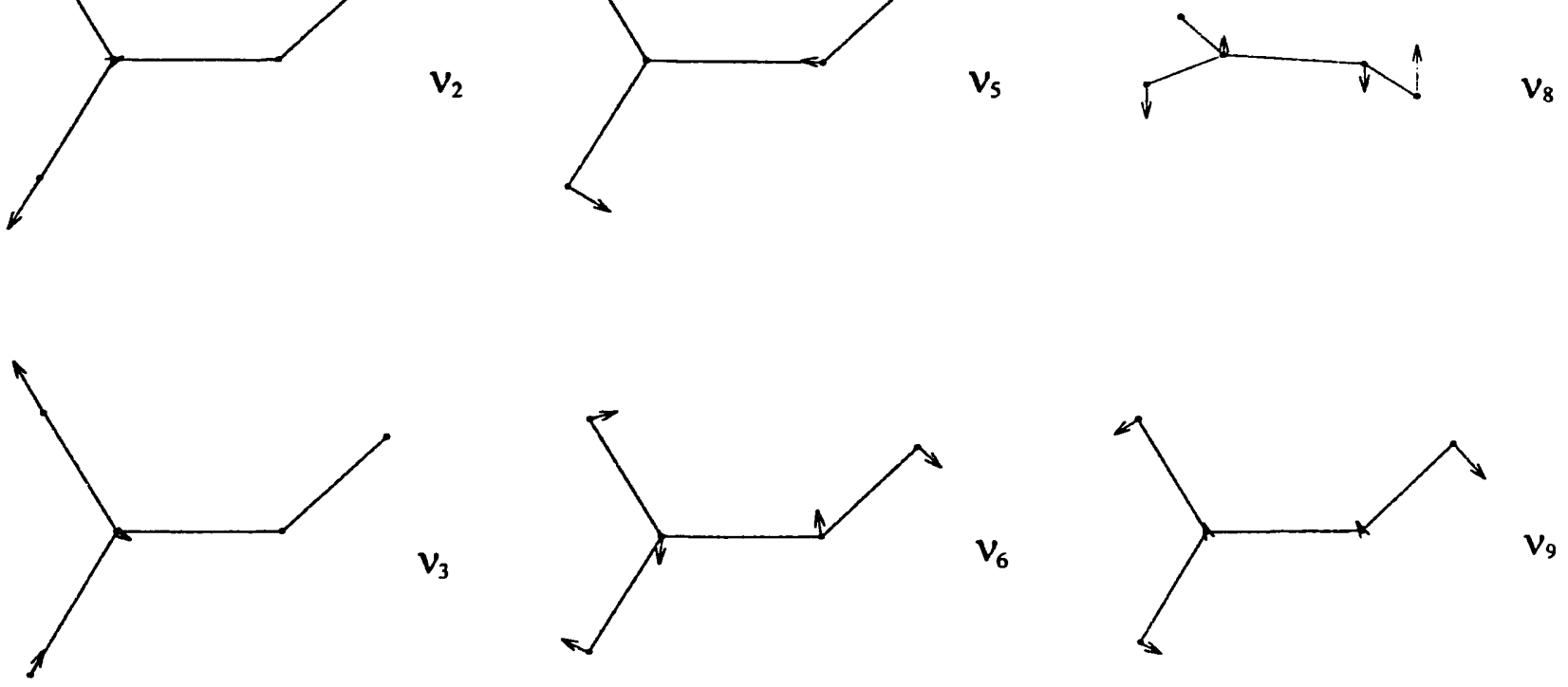

$V_{9}$

Fig. 4. The vibrational normal modes of classical $C_{2} H_{3} \tilde{X}^{2} A^{\prime}$.

After completing the optimization, we proceeded to calculate the fundamental vibrational frequencies of $\mathrm{C}_{2} \mathrm{H}_{3} \tilde{\mathrm{X}}^{2} \mathrm{~A}^{\prime}$ by diagonalizing the force-constant matrix and transforming the dipole-moment gradient to normal co-ordinates. The calculated fundamental vibrational frequencies of $\mathrm{C}_{2} \mathrm{H}_{3} \tilde{\mathrm{X}}^{2} \mathrm{~A}^{\prime}$ are also tabulated in Table 1. The nine vibrational normal modes are shown in Fig. 4.

\subsubsection{Electronic energies, ionizaticn potential and} dipole moment

In the MOLCAS calculations of $\mathrm{C}_{2} \mathrm{H}_{3}$, the methods from RASSCF to MRCI have been applied to compute the vertical transitions from the ground to the first, and to the second excited electronic states. The vertical ionization potential and permanent dipole moment of $\mathrm{C}_{2} \mathrm{H}_{3} \tilde{\mathrm{X}}^{2} \mathrm{~A}^{\prime}$ have also been included in the calculation. The generally contracted basis sets of atomic natural orbital (ANO) [24] have been used in the present study. At the beginning, smaller basis sets of the ANO-type contractions were used, such as [4s3p2d] for the carbon and [2s1p] for the hydrogen of $\mathrm{C}_{2} \mathrm{H}_{3}$ composed of the primitive sets of (14s9p4d) and (8s4p), respectively. More complete basis sets of ANO contractions, [4s3p2d1f] from primitive

Table 2

The selected frozen orbitals in the MOLCAS calculation ${ }^{\text {a }}$

\begin{tabular}{ll}
\hline $\begin{array}{l}\text { Number of } \\
\text { frozen orbitals }\end{array}$ & Frozen orbitals \\
\hline 2 & cores $a$ and $b$ \\
3 & cores $a$ and $b ;$ bond $c(\sigma)$ \\
4 & cores $a$ and $b ;$ bonds $a$ and $b$ \\
5 & cores $a$ and $b ;$ bonds $a, b$ and $c(\sigma)$ \\
6 & cores $a$ and $b ;$ bonds $a, b$ and $c(\sigma+\pi)$
\end{tabular}

${ }^{a}$ Cores $a$ and $b$ are $1 s$ electrons of $C_{1}$ and $C_{\because}$. 


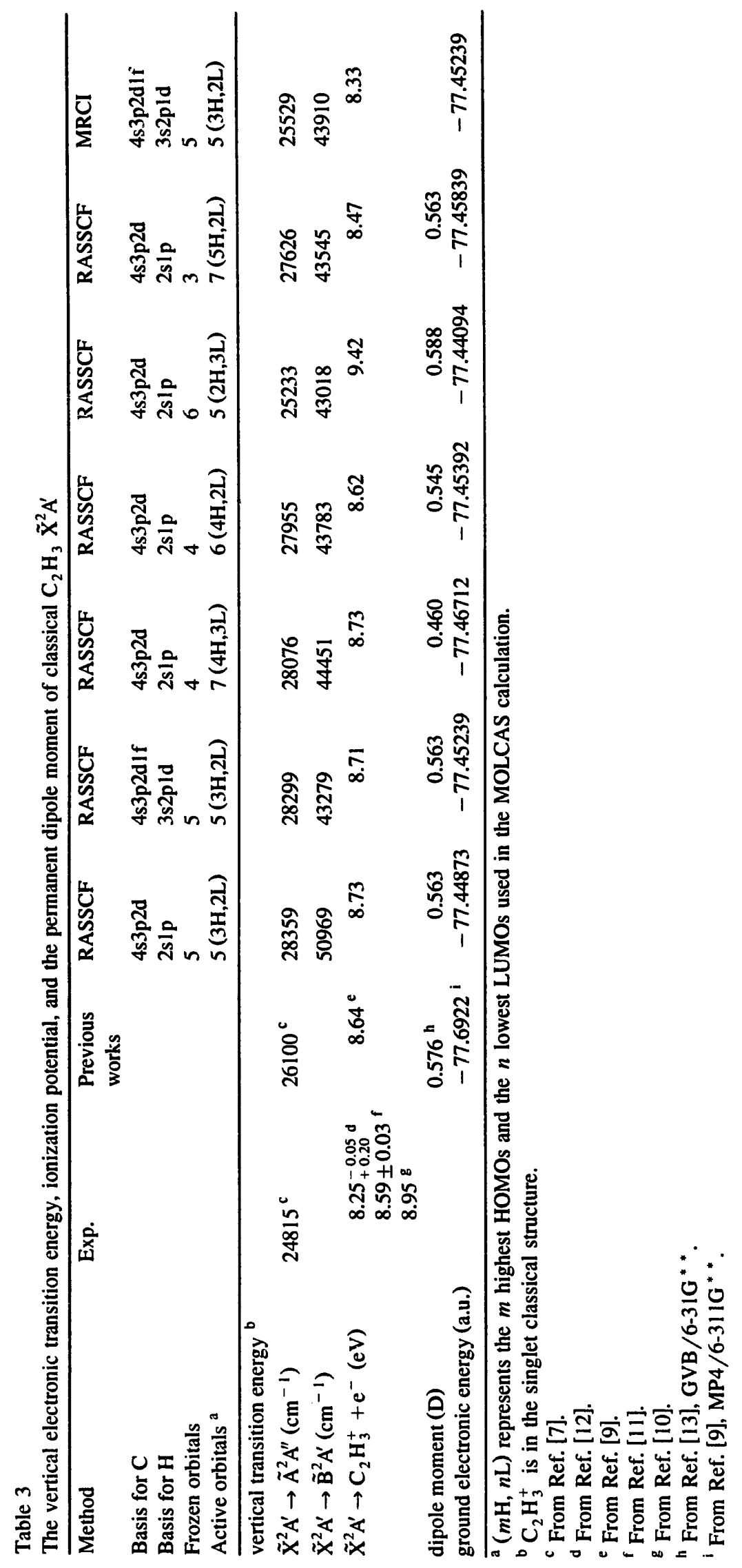


(14s9p4d3f) for the carbon and [3s2p1d] from (8s4p3d) for the hydrogen, have been employed later in the calculation. The sizes of the contracted basis sets for the smaller and for the more complete ones are 51 and 102, respectively.

Since the geometry optimization can not be carried out in the MOLCAS-2 program, the optimized equilibrium geometry of $\mathrm{C}_{2} \mathrm{H}_{3} \widetilde{\mathrm{X}}^{2} \mathrm{~A}^{\prime}$, obtained from the ACES II calculation using $\operatorname{CCSD}(T)$ and PVTZ/DZP, has been transferred into the MOLCAS computation to calculate the vertical transitions from the ground $(\tilde{\mathrm{X}})$ to the first excited $(\tilde{\mathrm{A}})$, and to the second excited $(\tilde{B})$ electronic states of $\mathrm{C}_{2} \mathrm{H}_{3}$. We have tested various sets of frozen and active orbitals in the MOLCAS calculation. The selected frozen orbitals in different approaches are listed in Table 2 and the corresponding labelling for the chemical bonds in $\mathrm{C}_{2} \mathrm{H}_{3}$ is shown in Fig. 3. We have taken the high occupied and the low virtual molecular orbitals of $\mathrm{C}_{2} \mathrm{H}_{3}$, shown in Table 3 , as a restricted active space (RAS). From the occupied molecular orbitals, the electronic configurations for the $\tilde{\mathrm{X}}, \tilde{\mathrm{A}}$, and $\tilde{\mathrm{B}}$ states of $\mathrm{C}_{2} \mathrm{H}_{3}$ are $\left(1 \mathrm{a}^{\prime}\right)^{2}\left(2 \mathrm{a}^{\prime}\right)^{2}\left(3 \mathrm{a}^{\prime}\right)^{2}$ $\left(4 a^{\prime}\right)^{2}\left(5 a^{\prime}\right)^{2}\left(6 a^{\prime}\right)^{2}\left(1 a^{\prime \prime}\right)^{2}\left(7 a^{\prime}\right)^{1},\left(1 a^{\prime}\right)^{2}\left(2 a^{\prime}\right)^{2}\left(3 a^{\prime}\right)^{2}\left(4 a^{\prime}\right)^{2}$ $\left(5 a^{\prime}\right)^{2}\left(6 a^{\prime}\right)^{2}\left(1 a^{\prime \prime}\right)^{1}\left(7 a^{\prime}\right)^{2}$, and $\left(1 a^{\prime}\right)^{2}\left(2 a^{\prime}\right)^{2}\left(3 a^{\prime}\right)^{2}\left(4 a^{\prime}\right)^{2}$ $\left(5 a^{\prime}\right)^{2}\left(6 a^{\prime}\right)^{2}\left(1 a^{\prime \prime}\right)^{1}\left(7 a^{\prime}\right)^{1}\left(2 a^{\prime \prime}\right)^{1}$, respectively, where the $1 a^{\prime \prime}, 7 a^{\prime}$ and $2 a^{\prime \prime}$ molecular orbitals have, in turn, been characterized by $\pi$-bonding, $\sigma$-bonding (occupied by the single electron on $C_{1}$ in Fig. 3), and $\pi^{*}$-bonding. From the electronic configurations, we have been able to identify the symmetry of the ground, the first and the second excited electronic states of $\mathrm{C}_{2} \mathrm{H}_{3}$ (in terms of a $\mathrm{C}_{\mathrm{S}}$ molecular symme- try group) as $\tilde{\mathrm{X}}^{2} \mathrm{~A}^{\prime}, \tilde{\mathrm{A}}^{2} \mathrm{~A}^{\prime \prime}$ and $\tilde{\mathrm{B}}{ }^{2} \mathrm{~A}^{\prime}$, respectively.

The reference configurations for the $\tilde{X}^{2} A^{\prime}, \tilde{A}^{2} A^{\prime \prime}$, $\tilde{B}{ }^{2} A^{\prime}$ electronic states of $C_{2} H_{3}$, and the vinyl cation used in the calculations are listed in Table 4. The resulted vertical transition energies, ionization potential and permanent dipole moment from the RASSCF calculations are tabulated in Table 3. After using the GUGA selection reference, we have tried an MRCI method with the basis sets of ANO contractions, [4s3p2d1f] for the carbon and [3s2p1d] for the hydrogen, to calculate the vertical electronic transitions of $\tilde{\mathrm{A}}^{2} \mathrm{~A}^{\prime \prime} \leftarrow \tilde{\mathrm{X}}^{2} \mathrm{~A}^{\prime}$ and $\tilde{\mathrm{B}}^{2} \mathrm{~A}^{\prime} \leftarrow \tilde{\mathrm{X}}^{2} \mathrm{~A}^{\prime}$ and the vertical ionization potential of $\mathrm{C}_{2} \mathrm{H}_{3}$. In the GUGA selection, five frozen and five active orbitals have been chosen. For the active orbitals, three HOMO, and two LUMO, were involved in the calculation. The MRCI results are listed in Table 3. In comparison with the experimental values for the vertical transition in $\tilde{\mathrm{A}}^{2} \mathrm{~A}^{\prime \prime} \leftarrow \tilde{\mathrm{X}}^{2} \mathrm{~A}^{\prime}$ and the vertical ionization potential of $\mathrm{C}_{2} \mathrm{H}_{3}$, the accuracy of the computational procedures in the present calculation has been tested, and will be discussed in Section 3.

\subsection{Intramolecular rearrangement}

\subsubsection{Isomerization}

In the study of the hydrogen-migration in $\mathrm{C}_{2} \mathrm{H}_{3}$ $\tilde{X}^{2} A^{\prime}$, the energy difference between the classical ( 1 in Fig. 1) and the non-classical (3 in Fig. 1) isomers has been calculated exclusively with the ACES II program. At the beginning of the optimization for the non-classical $\mathrm{C}_{2} \mathrm{H}_{3}$, we tried a full optimization

Table 4

The reference configurations for the $\tilde{X}^{2} A^{\prime}, \tilde{A}^{2} A^{\prime \prime}$ and $\tilde{B}^{2} A^{\prime}$ electronic states of $C_{2} H_{3}$ and the vinyl cation ${ }^{a}$

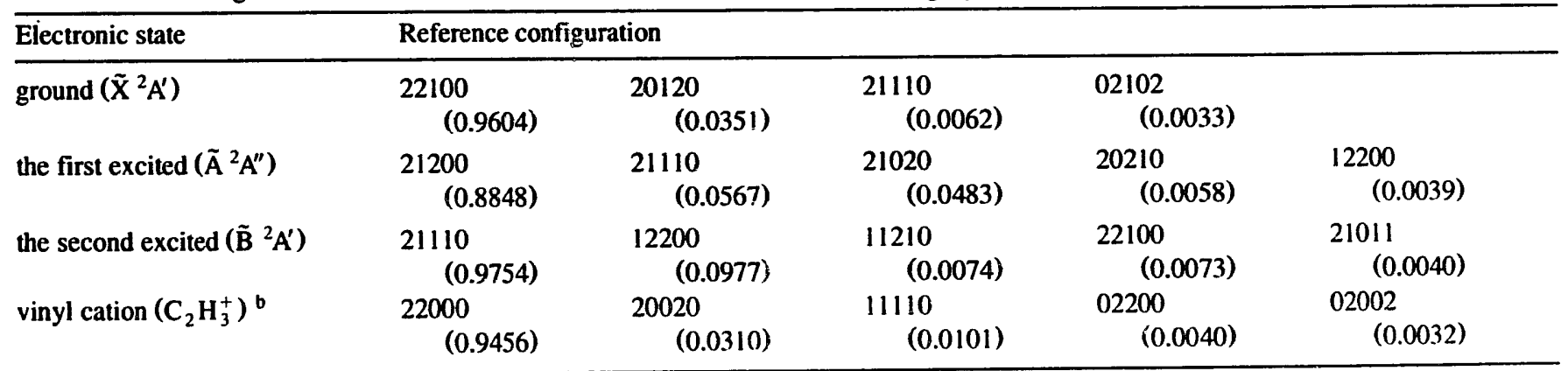

The number in parentheses represents a weight for the configuration used in the MRCl calculation.

${ }^{b} \mathrm{C}_{2} \mathrm{H}_{3}^{+}$is in the singlet classical structure. 


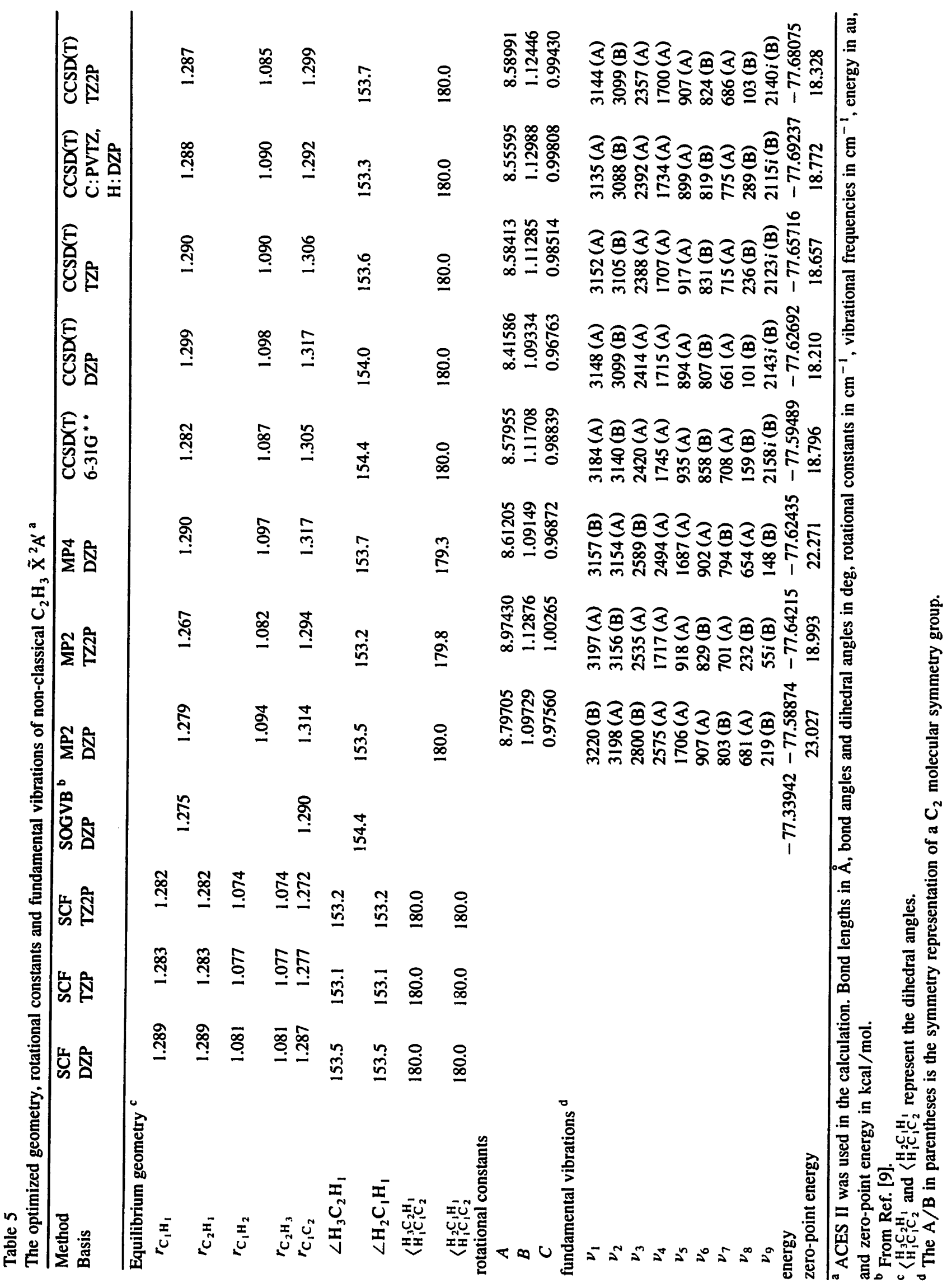




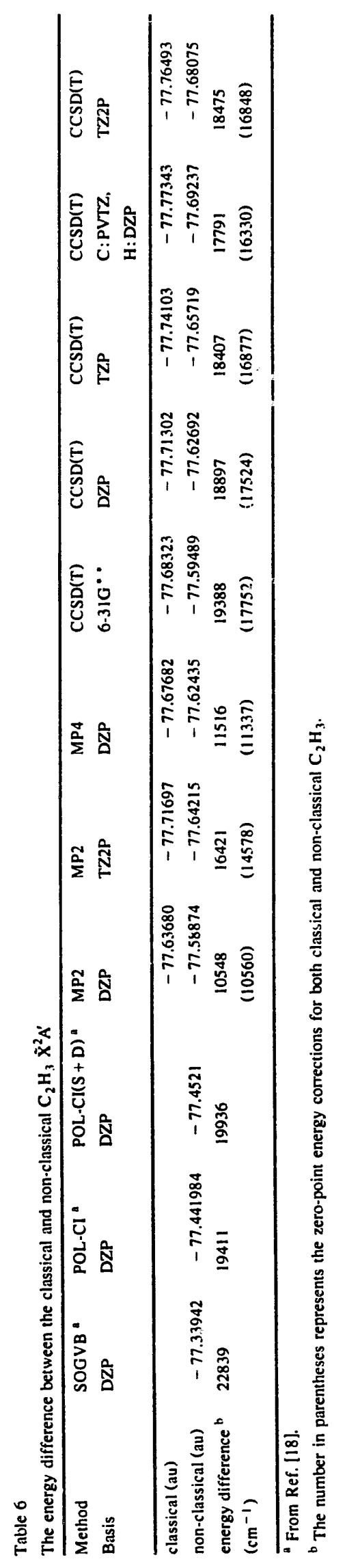




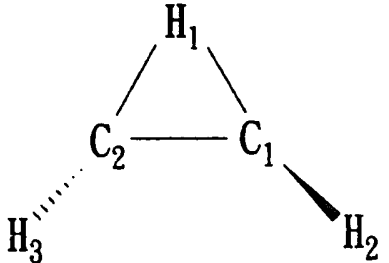

Fig. 5. The atomic labelling of non-classical $\mathrm{C}_{2} \mathrm{H}_{3} \tilde{\mathrm{X}}^{2} \mathrm{~A}^{\prime}$. process (including nine internal co-ordinates) using an SCF method and the Dunning basis sets of DZP, TZP and TZ2P. The optimized results are listed in Table 5 and the corresponding atomic labelling is shown in Fig. 5. The optimized non-classical $\mathrm{C}_{2} \mathrm{H}_{3}$ is essentially planar and possessed of $\mathrm{C}_{2 \mathrm{v}}$ symmetry. In the later calculations with higher-level methods,

Table 7

The optimized geometry, rotational constants, and fundamental vibrations of the transition state of $\mathrm{C}_{2} \mathrm{H}_{3} \tilde{\mathrm{X}}^{2} \mathrm{~A}^{\prime}{ }^{\mathrm{a}}$

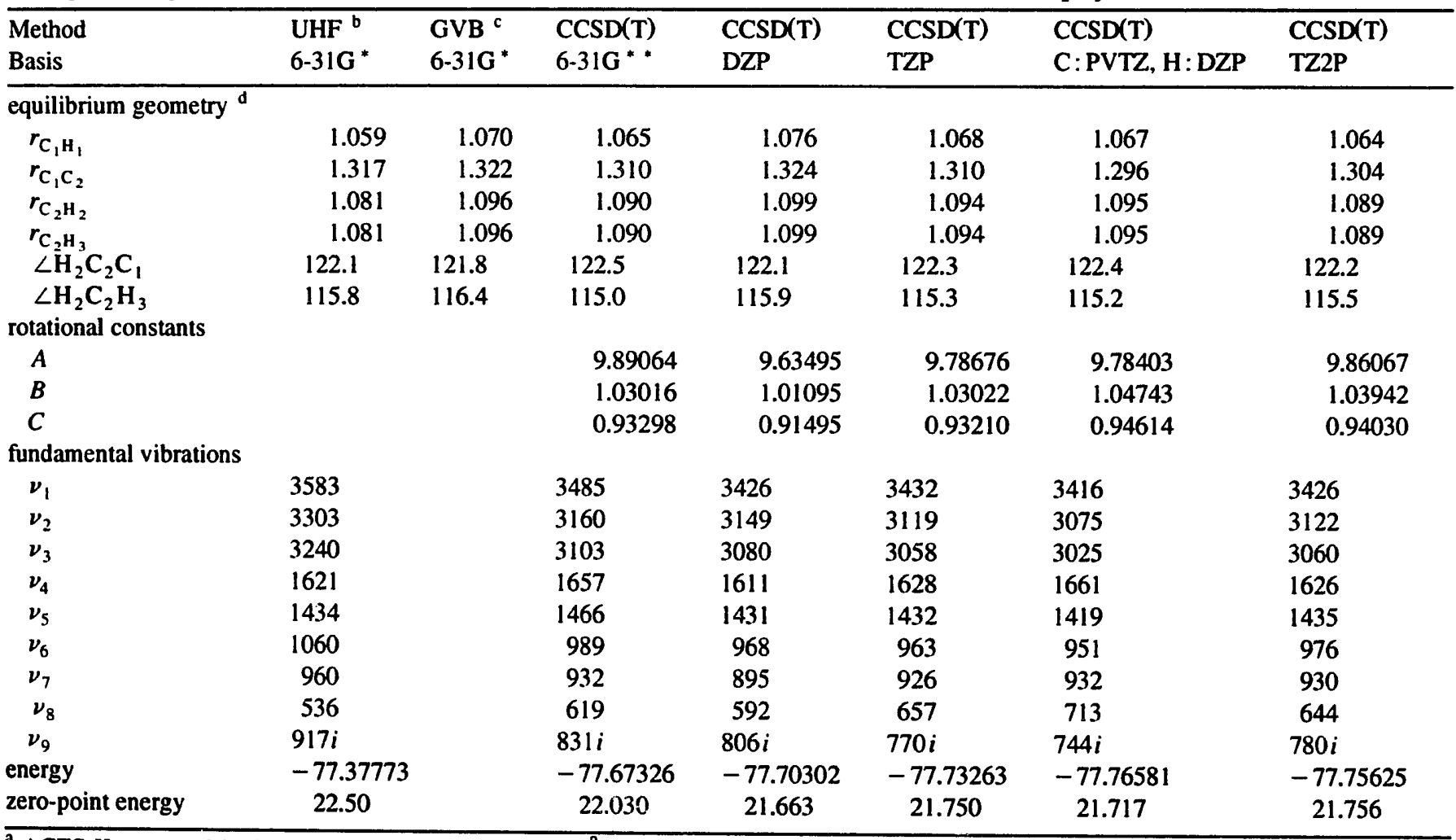

aCES II was used in the calculation. Bond lengths in $\AA$, bond angles and diheral angles in deg, rotational constants in $\mathrm{cm}^{-1}$, vibrational frequencies in $\mathrm{cm}^{-1}$, energy in au and zero-point energy in $\mathrm{kcal} / \mathrm{mol}$.

${ }^{b}$ Ref. [8].

c Ref. [13].

The atomic labeling is shown in Fig. 3 except that the $H_{1}$ is along the line with $C_{1}=C_{2}$.

Table 8

The calculated barrier height for the rocking motion of $\alpha-\mathrm{H}$ in $\mathrm{C}_{2} \mathrm{H}_{3} \tilde{\mathrm{X}}^{2} \mathrm{~A}^{\prime}$

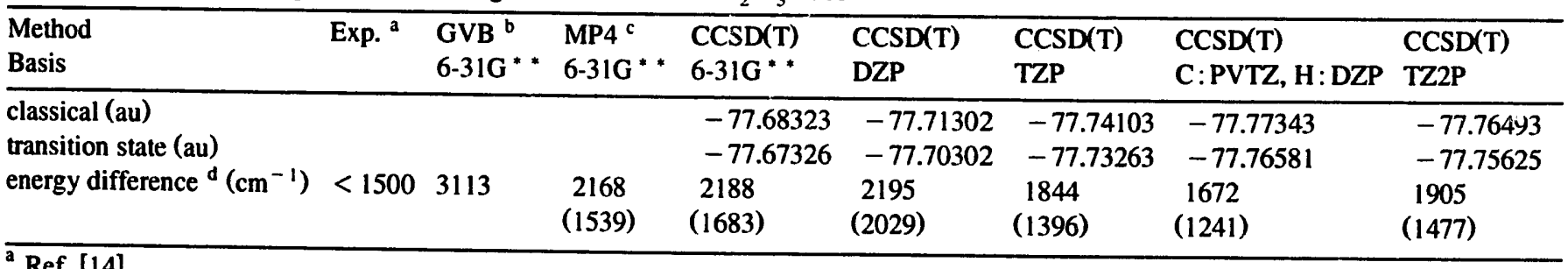

\footnotetext{
Ref. [14].

bef. [13].

c Ref. [8].

The number in parentheses represents the zero-point energy corrections for both classical and transition state of $\mathrm{C}_{2} \mathrm{H}_{3}$.
} 
Table 9

The optimized geometry and energy difference of the isomeric $\mathrm{C}_{2} \mathrm{H}_{2}{ }^{\text {a }}$

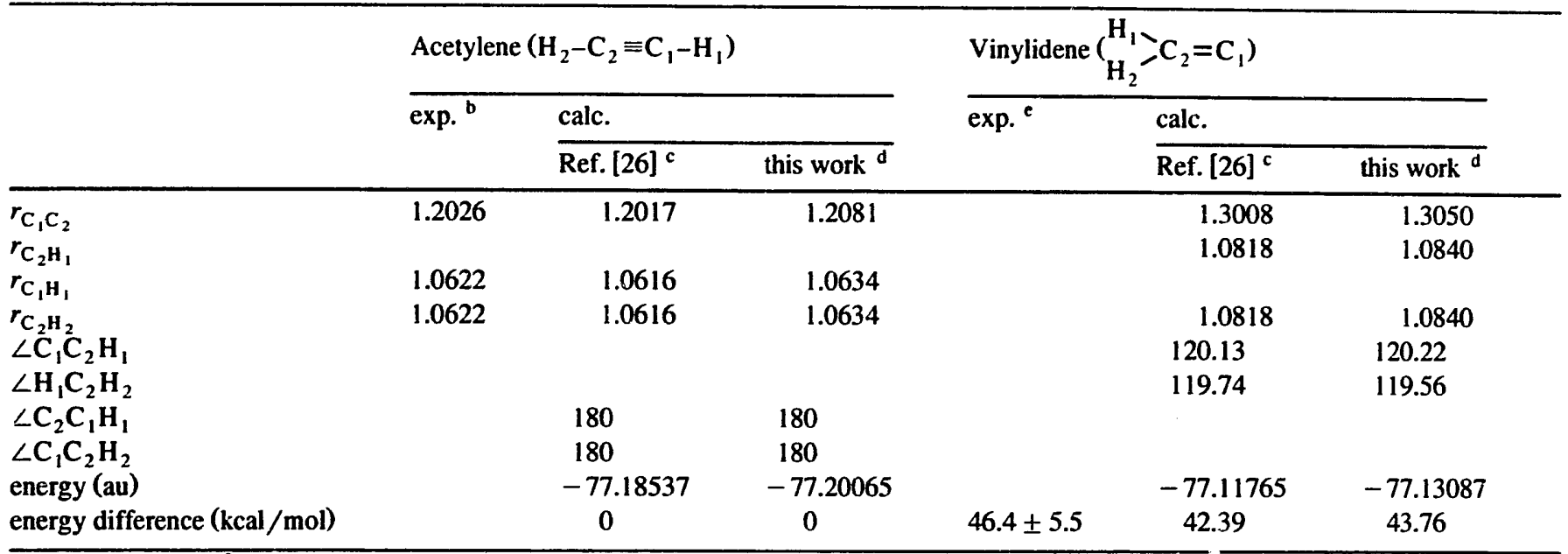

\footnotetext{
a Bond lengths in $\AA$, bond angles in deg.

b From Ref. [25].

c CSD/TZ2P was used in the calculation.

d $\operatorname{CCSD}(\mathrm{T}) / \mathrm{TZ2P}$ is used in the calculation.

From Ref. [27].
}

MBPT and $\operatorname{CCSD}(\mathrm{T})$, we have restricted the nonclassical $\mathrm{C}_{2} \mathrm{H}_{3}$ to be of $\mathrm{C}_{2}$ symmetry with five internal co-ordinates in the optimization. The optimized structures from various methods and basis sets are tabulated in Table 5 , in which the computed fundamental vibrational frequencies of the nonclassical $\mathrm{C}_{2} \mathrm{H}_{3}$ are also listed. In the $\operatorname{CCSD}(\mathrm{T})$ calculations for the vibrations of the non-classical $\mathrm{C}_{2} \mathrm{H}_{3}$, an imaginary vibrational frequency was always found, thus indicating the non-classical structure as an unstable isomer corresponding to a transition state on the molecular potential energy hypersurface. Comparisons for the calculated energy difference between the non-classical and the classical isomers of $\mathrm{C}_{2} \mathrm{H}_{3}$ are listed in Table 6.

\subsection{2. $\alpha-H$ rocking motion}

In a recent observation of the $\nu_{7}$ vibrational band in $\mathrm{C}_{2} \mathrm{H}_{3} \tilde{\mathrm{X}}^{2} \mathrm{~A}^{\prime}$, Kanamori et al. [14] have reported that the $\alpha$-hydrogen $\left(\mathrm{H}_{1}\right.$ in Fig. 3) of $\mathrm{C}_{2} \mathrm{H}_{3}$ is rocking back and forth around the two equivalent $\mathrm{sp}^{2}$ positions of the $\mathrm{C}_{1}$ atom, corresponding to a tunnelling motion in a double-minimum potential. In this study, we have tried to accurately calculate the barrier of the rocking motion by using the ACES II program. We have optimized the planar transition state ( 2 in Fig. 1) and calculated its fundamental vibrational frequencies. The results are listed in Table
7 with the similar atomic labelling as in Fig. 3 except that $\mathrm{H}_{1}$ is along $\mathrm{C}_{1}=\mathrm{C}_{2}$. The energy comparison between the transition state and the classical structure of $\mathrm{C}_{2} \mathrm{H}_{3}$ (1 in Fig. 1), which is located in the global minimum of the potential energy hypersurface, is shown in Table 8.

\subsection{Dissociation of $\mathrm{C}_{2} \mathrm{H}_{3} \tilde{X}^{2} A^{\prime}$}

In calculating the dissociation of $\mathrm{C}_{2} \mathrm{H}_{3} \tilde{\mathrm{X}}^{2} \mathrm{~A}^{\prime}$, the decomposition channels to acetylene and to vinylidene have been considered. The $\operatorname{CCSD}(\mathrm{T})$ method and TZ2P basis set were used in the calculation with the ACES II program. The dissociation energies for $\mathrm{C}_{2} \mathrm{H}_{3} \rightarrow \mathrm{HCCH}+\mathrm{H}$ and $\mathrm{C}_{2} \mathrm{H}_{3} \rightarrow \mathrm{H}_{2} \mathrm{CC}+\mathrm{H}$ are calculated to be 40.70 and $84.46 \mathrm{kcal} / \mathrm{mol}$, respectively. The optimized geometries of acetylene and vinylidene and the energy difference between these two isomers are listed in Table 9.

\section{Discussion}

\subsection{Molecular structure}

3.1.1. Equilibrium geometry and vibrations of $\mathrm{C}_{2} \mathrm{H}_{3}$ $\tilde{X}^{2} A^{\prime}$

Comparing the experimental values, the optimized geometry for the classical structure of $\mathrm{C}_{2} \mathrm{H}_{3} \tilde{\mathrm{X}}^{2} \mathrm{~A}^{\prime}$ 
(in Table 1) has shown a better accuracy for the CCSD(T) method than for MP2 and MP4. The use of $6-31 G^{* *}$ in the $\operatorname{CCSD}(\mathrm{T})$ calculation seems to have a fairly good result in this case. While the structure calculated from Dunning's DZP basis set turned out to be not quite satisfactory, the triple zeta polarizations have much improved the results, especially for $\angle C_{2} C_{1} H_{1}$. The calculated rotational constants $(A$, $B$, and $C$ ) using PVTZ/DZP or TZ2P in CCSD(T) are very close to the experimental values. Nevertheless, one should note that the observed geometry is for the vibrational ground state and may differ slightly from the calculated equilibrium structure. Moreover, the observed rotational constants are responsible for a geometry of $\mathrm{C}_{2 \mathrm{v}}$ effective symmetry in $\mathrm{C}_{2} \mathrm{H}_{3}$, while the calculated one is of $\mathrm{C}_{\mathbf{s}}$. The slightly larger rotational constant $A$ in the observation, in comparison with the calculated one, is in line with reasoning the linearity along $\mathrm{H}_{1} \mathrm{C}_{1} \mathrm{C}_{2}$ due to $\alpha-\mathrm{H}$ tunnelling.

The fundamental vibrational frequencies of the classical $\mathrm{C}_{2} \mathrm{H}_{3} \tilde{\mathrm{X}}^{2} \mathrm{~A}^{\prime}$ obtained from the calculation are also tabulated in Table 1. As mentioned before, $\nu_{7}$ has the strongest infrared intensity, and is the only vibrational mode observed so far. In view of this $\nu_{7}$ vibration, poor vibrational frequencies resulted from the calculations at levels of SCF and MP. The $\operatorname{CCSD}(T)$ calculations, on the other hand, have given quite satisfactory results for the $\nu_{7}$ vibrational frequency, indicative of the substantial improvement for the potential energy hypersurface due to electron correlation.

\subsubsection{Electronic energies, ionization potential and dipole moment}

In comparison with the observed vertical transition energies of $\mathrm{C}_{2} \mathrm{H}_{3} \tilde{\mathrm{A}}^{2} \mathrm{~A}^{\prime \prime} \leftarrow \tilde{\mathrm{X}}^{2} \mathrm{~A}^{\prime}\left(24815 \mathrm{~cm}^{-1}\right)$ and of the ionization potential $(8.25 \mathrm{eV})$, the calculated values (in Table 3 ) have gradually approached the experimental results from the uses of RASSCF to MRCI. The calculated $25529 \mathrm{~cm}^{-1}$ for $\tilde{A}^{2} A^{\prime \prime} \leftarrow \tilde{X}^{2} A^{\prime}$ and $8.33 \mathrm{eV}$ for the ionization potential from the MRCI method are in excellent agreement with the observations. The small deviations between the calculated and the experimental values, i.e. only 714 $\mathrm{cm}^{-1}$ for $\tilde{\mathrm{A}}^{2} \mathrm{~A}^{\prime \prime} \leftarrow \tilde{\mathrm{X}}^{2} \mathrm{~A}^{\prime}$ and $80 \mathrm{meV}$ for the ionization potential, have demonstrated a very good quality in the present computation. The vertical transition energy of $43910 \mathrm{~cm}^{-1}(\sim 228 \mathrm{~nm})$ for $\tilde{B}{ }^{2} A^{\prime} \leftarrow$
$\tilde{\mathrm{X}}^{2} \mathrm{~A}^{\prime}$, obtained from the MRCI calculation, will be very helpful for us to experimentally search for the undiscovered $\tilde{B}{ }^{2} \mathrm{~A}^{\prime}$ state of $\mathrm{C}_{2} \mathrm{H}_{3}$ by laser spectroscopy. The transition moment of $\widetilde{\mathrm{B}}^{2} \mathrm{~A}^{\prime} \leftarrow \tilde{\mathrm{X}}^{2} \mathrm{~A}^{\prime}$ should be substantial for spectroscopic observation due to its $\pi^{*} \leftarrow \pi$ character. The bond orders between the $\mathrm{C}-\mathrm{C}$ of $\mathrm{C}_{2} \mathrm{H}_{3}$ for the $\tilde{\mathrm{X}}, \tilde{\mathrm{A}}$ and $\tilde{\mathrm{B}}$ electronic states are $2,1 \frac{1}{2}$ and 1 , respectively. The bond-order calculation is indeed reconciled with the long vibrational progression, due to the $\mathrm{C}-\mathrm{C}$ stretch mode, observed in $\mathrm{C}_{2} \mathrm{H}_{3} \quad \tilde{\mathrm{A}}^{2} \mathrm{~A}^{\prime \prime} \leftarrow \overline{\mathrm{X}}^{2} \mathrm{~A}^{\prime}$ [7]. The permanent dipole moment in $\mathrm{C}_{2} \mathrm{H}_{3} \tilde{\mathrm{X}}^{2} \mathrm{~A}^{\prime}$ obtained from this work is also in good agreement with the previous generalized valence bond wavefunction calculation [13].

\subsection{Intramolecular rearrangement}

\subsubsection{Isomerization}

The optimized geometry, rotational constants and vibrational frequencies of the non-classical $\mathrm{C}_{2} \mathrm{H}_{3}$ $\tilde{\mathrm{X}}^{2} \mathrm{~A}^{\prime}$ are listed in Table 5. The shortening of the $\mathrm{C}-\mathrm{C}$ bond-length in the non-classical $\mathrm{C}_{2} \mathrm{H}_{3} \tilde{\mathrm{X}}^{2} \mathrm{~A}^{\prime}$, in comparison with that of the classical structure, is caused by the bridging hydrogen, $\mathrm{H}_{1}$, the presence of which results in a doubly occupied orbital which resembles a $\mathrm{C}-\mathrm{C} \pi$-bonding orbital. In all of the $\operatorname{CCSD}(\mathrm{T})$ calculations, the imaginary vibrational frequency around $2100 \mathrm{~cm}^{-1}$ has indicated the very unstable nature of the non-classical isomeric structure. In Table 6, the energy difference between the classical and non-classical structures of $\mathrm{C}_{2} \mathrm{H}_{3}$ is represented. Including zero-point energy, the nonclassical isomer has been found to lie at least 47 $\mathrm{kcal} / \mathrm{mol}$ above the classical, and energetically far above the dissociation threshold $(40.70 \mathrm{kcal} / \mathrm{mol})$ of $\mathrm{C}_{2} \mathrm{H}_{3} \rightarrow \mathrm{HCCH}+\mathrm{H}$. The large energy difference between the two isomers and the unstable nature of the non-classical structure have made the isomerization process in $\mathrm{C}_{2} \mathrm{H}_{3}$ quite a challenge for spectroscopic observation.

\subsection{2. $\alpha-H$ rocking motion}

In the determination of the barrier height for $\alpha-\mathrm{H}$ tunnelling in $\mathrm{C}_{2} \mathrm{H}_{3} \tilde{\mathrm{X}}^{2} \mathrm{~A}^{\prime}$, we have optimized the transition state ( 2 in Fig. 1) as listed in Table 7. The vibrational frequencies associated with the transition state have accordingly shown an imaginary value 
responsible for this saddle-point on the potential energy hypersurface. The calculated barrier height for the rocking motion of $\alpha-\mathrm{H}$ in $\mathrm{C}_{2} \mathrm{H}_{3} \quad \tilde{\mathrm{X}}^{2} \mathrm{~A}^{\prime}$ is tabulated in Table 8 . The barriers with zero-point energy correction, computed from CCSD(T)/Dunning's triple zeta polarizations, are in excellent agreement with the upper bound limit of $<1500$ $\mathrm{cm}^{-1}$ determined by high-resolution infrared spectroscopy [14].

\subsection{Dissociation of $C_{2} H_{3} \tilde{X}^{2} A^{\prime}$}

In comparison with the experimental values of $80.0 \pm 5.0 \mathrm{kcal} / \mathrm{mol}$ for the dissociation of $\mathrm{C}_{2} \mathrm{H}_{3} \rightarrow$ $\mathrm{H}_{2} \mathrm{CC}+\mathrm{H}$ reported by Ervin et al. [27], the calculated $84.46 \mathrm{kcal} / \mathrm{mol}$ is in agreement with the measurement. The calculated energy difference of $\mathbf{4 3 . 7 6}$ $\mathrm{kcal} / \mathrm{mol}$ between the isomers of acetylene and vinylidene is also consistent with the spectroscopic determination of $46.4 \pm 5.5 \mathrm{kcal} / \mathrm{mol}$ [27].

\section{Conclusion}

We have carried out a systematic study of the molecular structure (including equilibrium geometry, vibrational frequencies and intensities, electronic energies, ionization potential and dipole moment), the intramolecular rearrangement (isomerization and $\alpha-\mathrm{H}$ rocking motion) and the dissociation of $\mathrm{C}_{2} \mathrm{H}_{3}$ with high-level ab initio calculations using ACES II and MOLCAS-2 programs. In view of the calculated and the experimental values, such as the equilibrium geometry of $\mathrm{C}_{2} \mathrm{H}_{3} \tilde{\mathrm{X}}^{2} \mathrm{~A}^{\prime}$, the transition energy of $\tilde{\mathrm{A}}^{2} \mathrm{~A}^{\prime \prime} \leftarrow \tilde{\mathrm{X}}^{2} \mathrm{~A}^{\prime}$, the ionization potential, the barrier height for the $\alpha-\mathrm{H}$ rocking motion and the $\mathrm{C}-\mathrm{H}$ dissociation energy, the computational accuracy in the present study has demonstrated to be of very good quality.

The vertical electronic transition $\vec{B}^{2} A^{\prime} \leftarrow \bar{X}^{2} A^{\prime}$ of $\mathrm{C}_{2} \mathrm{H}_{3}$ and the energy difference between the classical and non-classical isomers in $\mathrm{C}_{2} \mathrm{H}_{3} \tilde{\mathrm{X}}^{2} \mathrm{~A}^{\prime}$, resulted from the calculations in this work, have provided valuable information which will facilitate the forthcoming experimental studies in our laboratory. The calculated vibrational frequencies and infrared intensities of $\mathrm{C}_{2} \mathrm{H}_{3} \tilde{\mathrm{X}}^{2} \mathrm{~A}^{\prime}$ will assist the spectroscopic measurement for the unobserved vibrational modes. The knowledge from the calculated isomerization and dissociation processes in $\mathrm{C}_{2} \mathrm{H}_{3} \tilde{\mathrm{X}}^{2} \mathrm{~A}^{\prime}$ will help us in the experimental investigations to be carried out with high-resolution IR-UV laser-induced grating spectroscopy.

\section{Acknowledgement}

We thank Professor S.H. Lin and Dr. J.-W. Yu for their comments on this manuscript. Mr. ChungJen $\mathrm{Wu}$ is gratefully acknowledged for his computer drawing of Fig. 4. This work is supported, in part, by the National Science Council of Republic of China under grant No. NSC-84-2113-M-001-037 CT.

\section{References}

[1] H. Okabe, Photochemistry of small molecules (Wiley, New York, 1978).

[2] W.C. Gardiner, Jr., ed., Combustion chemistry (Springer, New York, 1984).

[3] I.K. Puri, ed., Environmental implications of combustion processes (CRC Press, Boca Raton, 1993).

[4] A. Fahr, A. Laufer, R. Klein and W. Braun, J. Phys. Chem. 95 (1991) 3218.

[5] D.J. Donaldson, I.V. Okuda and J.J. Sloan, Chem. Phys. 193 (1995) 37.

[6] O. Simamura, in: Topics in stereochemistry, Vol. 4, eds., E.L. Eliel and N.L. Allinger (Wiley, New York, 1969) p. 1.

[7] H.E. Hunziker, H. Kneppe, A.D. McLean, P. Siegbahn and H.R. Wendt, Can. J. Chem. 61 (1983) 993.

[8] M.N. Paddon-Row and J.A. Pople, J. Phys. Chem. 89 (1985) 2768.

[9] L.A. Curtiss and J.A. Pople, J. Chem. Phys. 88 (1988) 7405.

[10] F.P. Lossing, Can. J. Chem. 49 (1971) 357.

[11] J. Berkowiz, C.A. Mayhew and B. Ruscic, J. Chem. Phys. 88 (1988) 7396.

[12] J.A. Blush and P. Chen, J. Phys. Chem. 96 (1992) 4138.

[13] M. Dupuis and J.J. Wendoloski, J. Chem. Phys. 80 (1984) 5696.

[14] H. Kanamori, Y. Endo and E. Hirota, J. Chem. Phys. 92 (1990) 197.

[15] R.A. Shepherd, TJ. Doyle and W.R.M. Graham, J. Chem. Phys. 89 (1988) 2738.

[16, M.W. Crofton, M.F. Jagod, B.D. Rehfuss and T. Oka, J. Chem. Phys. 91 (1989) 5139, and references therein.

[17] C. Liang, T.P. Hamilton and H.F. Schaefer III, J. Chem. Phys. 92 (1990) 3653, and references therein.

[18] L.B. Harding, J. Am. Chem. Soc. 103 (1981) 7469.

[19] I.M.B. Nielsen, C.L. Janssen, N.A. Burton and H.F. Schaefer III, J. Phys. Chem. 96 (1992) 2490. 
[20] C.E. Hamilton, J.L. Kinsey and R.W. Field, Annu. Rev. Phys. Chem. 37 (1986) 493.

[21] M.A. Buntine, D.W. Chandler and C.C. Hayden, J. Chem. Phys. 97 (1992) 707.

[22] ACES II is authored by J.F. Stanton, J. Gauss, J.D. Watts, W.J. Lauderdale and R.J. Bartlett., University of Florida, USA.

[23] MOLCAS is authored by K. Andersson, M.P. Fülscher, G.
Karlstrom, R. Lindh, P.-A. Malmqvist, J. Olsen B.O. Roos and A.J. Sadlej, University of Lund, Sweden.

[24] J. Almlöf and P.R. Taylor, J. Chem. Phys. 86 (1987) 4070. [25] G. Strey and I.M. Mills, J. Mol. Spectry. 59 (1976) 103.

[26] J.F. Stanton, C.-M. Huang and P.G. Szalay, J. Chem. Phys. 101 (1994) 356.

[27] K.M. Ervin, J. Ho and W.C. Lineberger, J. Chem. Phys. 91 (1989) 5974. 